\title{
Winning approval to implement DAM and Marketing Workflow Management from the CFO and CEO without being thrown out on your b...
}

\begin{abstract}
Guy R. Powell
has over 20 years experience in senior level sales and marketing in the US and worldwide, both on the client and consulting sides. Through his DemandROMI consulting and training practice, he has trained senior marketers throughout the world representing over $\$ 1$ tn in revenue, many of which lead to follow-on consulting engagements. His strategic marketing consulting career began as management consultant with ATKearney on a wide range of projects, for both mid-tier and Global 100 companies, providing strategic assessments and re-alignments and business turn-arounds. Prior to founding DemandROMI (www.demandROMI.com), he served as VP of Sales \& Marketing for a number of companies delivering growth through innovative product, marketing and selling concepts. Direct industry experience includes consumer package goods, digital electronics, high tech, brewery, frozen food, automotive, cable and wire, consumer durables, media and entertainment and many others. He is the author of Return on Marketing Investment: Demand More from your Marketing and Sales Investments, outlining a common language and pragmatic approach for business-tobusiness marketing, executive management and sales to communicate and collaborate on marketing programmes directly supporting business and revenue goals. More information on this book can be found at www.returnonmarketing.net. Guy has an upcoming book that will help propel marketers to the next level of effectiveness. Sign up at www.DemandROMI.com/EvenMoreROMI.html.
\end{abstract}

Keywords: marketing effectiveness, marketing ROI, marketing operations management, digital asset management, marketing strategy

Abstract Marketers are at a crossroads. They can continue operating the way they have in the past or they can being to look at systematizing their infrastructure through mature technologies, such as Digital Asset Management (DAM) and Marketing Operations Management (MOM). They can continue to suffer short tenures or they can work to develop long-term value for their companies and their careers. It is now time to get the CEO and CFO on your side to implement systems that can improve marketing effectiveness, provide a strategic advantage and increase the value of the brand. This paper provides a framework with which to evaluate the potential ROI of a DAM/MOM system which can then be used as justification with the CEO and CFO. It stresses the language necessary for marketers to succeed in gaining approval. And it provides a few examples of how marketers can frame their arguments in terms the CEO and CFO can relate to.

Journal of Digital Asset Management (2007) 3, 191-195. doi:10.1057/palgrave.dam.3650090

Guy R. Powell DemandROMI - Prove and Improve your Marketing Performance(TM), 3355 Lenox Road STE 750, Atlanta, GA 30326, USA Tel: +17708339735 (c), +14048164344 (o) Fax: 4045047058 E-mail: gpowell@ demandROMI.com Web: www.DemandROMI. com; Blog: www. MarketingTactegy.com

\section{INTRODUCTION}

I talk about ROI all the time. For the last six years proving and improving marketing effectiveness has been my passion. It is one of the most important challenges for the marketing department ever since the technology bust. The free and easy spending of the 30-s spots at the Super Bowl by those no name internet companies is over. But it is one thing to talk about ROI on money spent outside of the company. It is another thing talking about ROI when it deals with inside the company. And yet to get the ear of the CFO and CEO we have to use their language - and it is spelled m-o-n-e-y. They will certainly listen to how an investment will build the brand and value for the company, but if it comes with savings attached their ears perk up, like those of an obedient collie.

This June there were a number of very interesting presentations and panel discussions on ROI at the recent Henry Stewart Conference in New York and I wanted to relate a few of them, 
because they can help us to sell marketing infrastructure technology to the folks with the purse strings - the CEO and CFO.

\section{ROI IS A SCARY THING}

$\mathrm{ROI}$ is a scary thing. Everyone in the company talks a great game of wanting to prove it, improve it, deliver more of it and take claim for it, but many are unwilling to try to actually do it, show it or to propose it because of those "unintended consequences".

Here is a case in point. I was surprised when I heard the presentation from Linda Kato from Nissan ('In the Fast Lane - Nissan Accelerates from 0-\$60 Million Assets Repurposed in 6 Months Flat') on her trials and tribulations with their DAM implementation. As soon as the Nissan financial guys heard there might be ROI, they came running. They claimed it and put it immediately to the bottom line. Instead of allowing the marketing department to determine how best to allocate the savings, finance took the savings right out of the budget. Spending was immediately cut to match the expected savings.

Unfortunately, everyone, including those even remotely involved with the Nissan Digital Asset Management project heard about it and they all went running, just like in the middle of the night when the light goes on and the cockroaches in the kitchen scatter to the winds. According to Kato, it took over two years to recover enough such that she was able to regain traction and actually implement the project. Say hello to the scary side of ROI.

Nevertheless, ROI is the language of the $\mathrm{CEO}$ and CFO, so let us make certain we can talk about it in the right context and use it to our advantage when we need to.

\section{MARKETING ROI FRAMEWORK}

After having spent the last six years of my professional life specializing in improving marketing ROI for small to large companies, B2B and Consumer, US and International, it is apparent that there are five areas with which you can improve marketing ROI (Figure 1):

- Strategy: Certainly strategy is at the top of the list when it comes to improving marketing effectiveness. I think you would agree that a marketing campaign run in context of a good strategy is going to deliver better results than the same type of campaign run in context of a bad strategy. But, since your strategy should not change that often, it is hard to improve marketing effectiveness by changing your strategy unless you can prove that the strategy you have is just not working.

- Creative: The AFLAC duck illustrated how successful good creative concepts can be in driving growth. The pre-duck growth rate was 12 per cent and the post-duck growth rate was 28 per cent and 29 per cent in the years immediately following the introduction of the new creative and there was little change in the marketing budget. ${ }^{1}$ Clearly, good creative can improve marketing effectiveness. Great creative can change an industry. This is why the agencies should get paid the big bucks.

- Execution: Marketing programs impact the bottom line in two dimensions:

- Program level: By executing specific programs as effectively as possible, marketers can improve their marketing ROI. If they buy their media better, if they time the flighting of the media placements better or if they train their sales force better they will deliver a higher ROI for the specific media.

o Mix level: By allocating resources to the marketing activities that provide a better ROI versus those that do not, we can deliver increased ROI without spending any additional funds. Marketing mix modeling is one way in which to determine which media are working, which are not and by how much.

- Infrastructure: This is where marketers can improve the effectiveness of their marketing department. If the marketing department can save money and time in the business of marketing, the company can save money or spend it on in-market activities. The company can become more competitive by being able to react faster to drive new initiatives or respond to competitive actions.

With the context clear on how to speak about where and how we can improve marketing ROI, now we can start to frame the discussion with the CEO and CFO.

\section{MARKETING ROI AND DAM/MOM}

Delivering marketing ROI from DAM and MOM projects has a number of facets. Not only can the company save money but it can be 


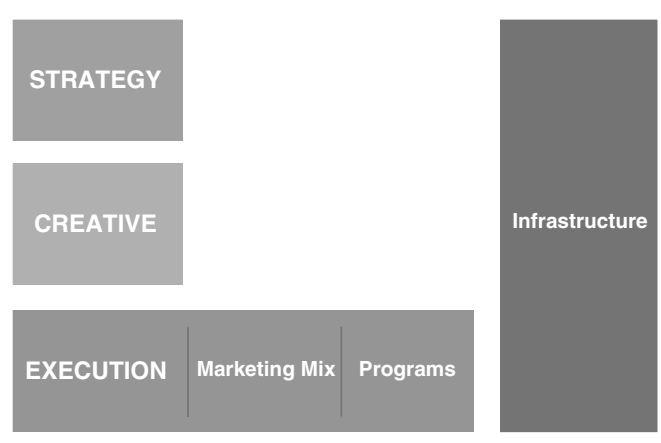

Figure 1: The marketing ROI framework: The new strategic advantage

more reactive in the marketplace and in many cases it can provide new source of revenues, improved brand engagement, better creative and better execution. As the demand for more marketing assets (not less) is driven by the increased use of the web, marketers also must find ways of delivering these assets at lower and lower incremental costs to stay competitive in the marketplace. DAM and MOM implementations can help do just that.

At the infrastructure level:

- Saving money: DAM/MOM systems reduce costs in a number of ways:

$\circ$ Errors are reduced, creative efforts are not duplicated, assets are re-used and shipping and handling costs can be drastically cut. Many of the presentations discussed this one aspect of cost savings and this has to be put at the top of the list.

$\circ$ The efficiency and effectiveness of the marketing department is increased. Search times for existing assets are lower. CD copying and shipping effort is drastically cut. Although there are a few areas where some efforts are increased, such as the initial cataloging and tagging effort, the net result is that the total effort is reduced. Marketing now has more time available to create more and better creative assets.

- Risk mitigation:The re-use of assets throughout the organization, both domestically and globally, often has interesting usage restrictions that can be directly controlled through a DAM system. DAM can easily manage licensing and copyright restrictions, so that fewer mistakes are made. And as lawyers are increasingly part of the workflow, major brands can make certain that the creative concepts do not open the company up to any unnecessary risk without having to delay the project completion times.

At the strategic level:

- Competitiveness: There are two components to improved competitiveness offered through the implementation of DAM/MOM systems:

- Improved simplified processes: Patrick Barwise' Simply Better ${ }^{2}$ states that executing the simple things simply better than the competition will lead to faster growth which in turn delivers a strategic advantage to the organization. Given that it is very difficult to sustain a competitive advantage through product features alone, operational advantages such as those accruing through improved marketing operations management, can deliver a sustainable competitive advantage.

- Response times: Although DAM/MOM systems do not change the strategy per se, they do deliver strategic advantage. They do this by allowing marketers to react faster to changing conditions in the marketplace. By executing faster, marketers deliver a strategic advantage translating into growth rates surpassing those of the competition. Wells Fargo was reported to have reduced their marketing process time from 12 weeks down to two weeks while Barclays Bank went from 12 down to eight. How much more competitive are these banks now that they can respond to competitive actions or react to market opportunities that much faster?

At the creative level:

- DAM/MOM systems deliver creative consistency across the country, across the globe and throughout the channel. With a systematic and workflow-based approach controlling the dissemination of assets, marketers can make certain that the desired creative assets are used in a timely and controlled fashion. Global roll-outs of global campaigns can be done on time even in the face of required translations and local language variations. One of the examples discussed was from Lexus. For a global luxury brand, DAM/MOM systems allow global brand consistency as the traveling affluent target segment is touched by the brand in New York, Tokyo, Dubai or anywhere else in the world.

- Brand engagement: Engagement with the brand can take place in many ways. It can take place at the dealer level, the consumer level or on the web. If the marketing infrastructure can deliver increased 
brand engagement among the company's target audiences, the systems provide an ROI. There were two great examples presented:

○ Harley-Davidson is considering ways for it to make digital assets available to its enthusiasts and dealers. In this way, the dealers and enthusiasts can receive the latest higher quality, branded images that engage the viewer in the way intended by the brand team.

- The San Diego Zoo and other public venues have thousands if not millions of images that are of value to their audiences. Kids need images for their school homework projects. Agencies need high-quality images to support their clients. If the zoo is able to provide them at the right price at the right time in the right format, the zoo can develop a new revenue stream and maintain increased brand engagement through the use of the these images.

At the execution level:

- DAM/MOM systems improve execution through the use of assets by allowing them to be created more quickly, less expensively and consistent with other media. This can deliver improved synergies across media in an integrated media campaign and thereby deliver improved response.

Each of these elements represents areas where DAM/MOM systems improve marketing's ability to deliver the brand message to the marketplace at least cost and risk with the most positive response. But wait. There are a few more arguments to support us when we go to the CFO and CEO.

\section{THE ARGUMENTS FOR DAM/ MOM}

Here are four arguments to help get buy-in for the implementation of DAM/MOM systems in your company:

$$
\text { "Money — it's a gas."3 }
$$

Marketers must learn to speak in the language of the CFO and CEO. Marketers speak the language of their consumers but they forget that they must also sell back to the organization and they need to speak in their language - m-o-n-e-y. Their language is not slogans, colors or jingles. It's "money". So we need to remember to frame the discussion around the implementation of these systems in that context.
Is marketing an asset or an expense?

One of the questions we need to ask ourselves when thinking about systems to manage the business of marketing is to put it in context of things that the CFO and CEO will understand and that is "if you can spend 100,000s of dollars (or millions, depending on the size of the company) managing cash, why can't we spend the same amount managing assets of similar value in the marketing department? Why is it, that marketing has systems based on a simple spreadsheet and the CFO has customized systems worth hundreds or thousands times that to manage cash? If we don't manage our marketing properly we won't have any cash, so isn't managing the business of marketing just as important as managing cash?”

By the way, if the CFO and CEO just think of marketing as an expense then we, as marketers, have done a terrible job of communicating with the $\mathrm{CEO}$ and $\mathrm{CFO}$ the true value of marketing's efforts. It may be an expense as far as the financial accounting is concerned, but marketing is an investment in the delivery of revenue this month, this quarter as well as next year and beyond.

If it's an asset, then...

How important is it to the company to manage an asset worth $\$ 10$ million? If the marketing department spent $\$ 10$ million to develop assets, that represents the acquisition cost of those assets. It is the same way to calculate the cost of a machine, a plant or a building. How important is it for the $\mathrm{CFO}$ to track assets? If a laptop, including software is worth $\$ 2,000, \$ 10$ million represents 500 laptops. How much effort do the finance and IT departments spend tracking 500 laptops? How many assettracking labels are on the bottom of your laptops, your office chairs and your whiteboards? Not only can the value of marketing assets easily reach the same levels as all of your office assets, in large organizations they can easily exceed them. If the finance department can invest thousands in tracking office assets, how can it 
be that marketing should not track their assets?

The good news is that this argument is finally starting to gain momentum in larger organizations. CFOs are starting to see the light.

Only sales and marketing can drive increased revenue

What is the value of an incremental dollar invested in marketing (and sales) versus anywhere else in the company? Investing in a new software system in the accounting department can only reduce costs. Investing in a new cost-cutting production method in the factory can also only save costs. Neither of these investments can increase revenue. The only place where investments can drive both increased profit and increased revenue is in sales and marketing. And which would a shareholder rather have? Increased profits alone or increased profits accompanied by increased revenue? So any investment to improve the business of marketing (and sales) has a significantly higher value than any other investment elsewhere in the company that can only reduce costs.

\section{CAN DAM/MOM INCREASE CMO TENURE?}

It is an abomination to the marketing profession that the average tenure of the top marketing officer is less than 24 months. Even worse, how can we put up with the comment from David Packard, stating that "marketing is too important to be left up to the marketing department?"

If marketers do not start improving the way we look at the marketing process and marketing ROI, tenures will continue to shrink and we will "get no respect." DAM/MOM installations combined with other systems and operational processes are beginning to deliver a systematic approach to the marketing process. Enterprise Marketing Management systems (EMM), of which DAM and MOM are a part, are also on the horizon. The great fear that these systems stifle creativity has not materialized. If anything it has freed up time and money to support and drive more creativity and better marketing. Isn't it time to get on board?

\section{CONCLUSION}

Marketers have a lot to gain through the implementation of Digital Asset Management and Marketing Operations Management systems. They can gain a competitive advantage, improve the creative execution and improve response in the marketplace. It may even lead to improved tenures and faster growth in our careers. It is now time for marketers to get on the ball and begin the process of transforming marketing from a tangled web of expense to a finely tuned machine of investment.

\section{Notes}

1 Bang! Getting Your Message Heard in A Noisy World by Linda Kaplan Thaler, Robin Koval, and Delia Marshall, 2003, Currency.

2 Simply Better: Winning and Keeping Customers by Delivering What Matters Most by Patrick Barwise and Sean Meehan, 2004, Harvard Business School Press.

3 Pink Floyd, Dark Side of the Moon. 